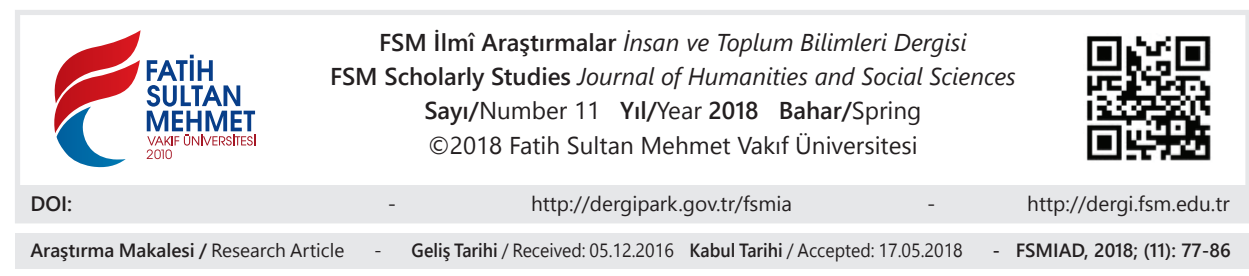

\title{
Afif Damadı Hattat Osman Efendi (?-1806)
}

Talip Mert

\section{Öz}

XVIII. asır hattatlarındandır. İyi derecede bir hattat olduğu yazılarından anlaşılmaktadır. Afif Damadı Osman Efendi yine VXIII. Asır hattatlarından Afif İbrahim (?-1768) Efendinin kızı Emetullah Hanımla (?-1770) evli olduğundan imzalarında hep kayın pederinin ismini kullanmış, bu sebeple de hat dünyasında o hep "Afif Damadı Osman Efendi veya Afif Damadı Deli Osman” diye meşhur olmuştur. Yayımlanan bu belgeler ile Deli Osman Efendi hakkında yeni bazı bilgiler ortaya çıkmış bulunmaktadır. Emetullah Hanımla ne kadar evli kaldıkları bilinmiyor. Fakat Emetullah Hanım kendisinden 36 sene önce vefat ettiğine göre çok uzun süren bir evlilik hayatları da her halde olmamıştı. Buna rağmen Osman Efendi belki eşinden dolayı, belki de kayın pederine olan aşırı sevgi ve saygısından dolayı Afif İbrahim Efendi'yi imzalarında hep yaşatmıştır.

Anahtar Kelimeler: Hattat, Afif İbrahim, Deli Osman, Emetullah Hanım.

\section{Calligraphist Osman Efendi, The Son in Law of Afif (?-1806)}

\section{Abstract}

Is an XVIII. century calligraphist. It can be ascertained that he was a good calligrapher from his works. Afif Damadi (son-in-law) Osman Efendi was married to the daughter, Emetullah Hanım (?-1770), of another XVIII. century calligraphist Afif İbrahim Efendi (?-1768) and because of this he used to pen his works in the name of his father-in-law and was subsequently always known in the world of calligraphy as "Afif Damadı Osman Efendi or Afif Damadı Deli Osman." With the publication of these records new facts have come to light with regard to Deli Osman Efendi. It is not known how long he was married to Emetullah Hanım for. However given that Emetullah Hanımla died 36 years before Deli Osman Efendi, it cannot be supposed that they had a long married life. Despite this, perhaps because of his wife or because of the deep love and respect he felt for his father-in-law, Deli Osman Efendi kept the memory of Afif İbrahim Efendi alive by always penning his works in his name.

Keywords: Hattat, Afif İbrahim, Deli Osman, Emetullah Hanım.

Öğr. Gör., Marmara Üniversitesi FEF Bilgi ve Belge Yönetimi Bölümü, İstanbul / Türkiye, tmert@marmara.edu.tr, orcid.org/0000-0003-2044-1527 
Hattat Osman Efendi veya Deli Osman veyahut en meşhur adıyla Afif İbrahim Damadı Osman Efendi XVIII. asır hattatlarındandır. Günümüze ulaşan eserlerinden anlaşıldığına göre Osman Efendi Osmanlı hat tarihinde iyi bir yere sahiptir. Mevcut kayıtlara göre onun Bülbül Deresi'nde doğmuş bir Üsküdarlı olduğu ve Üsküdar'da yaşayıp yine burada vefat ettiği ortaya çıkıyor. Sanat tarihimizde yer alan pek çok meşhur gibi Osman Efendi'nin de doğum tarihi belli değildir. Habib Efendi'nin yazdıklarının doğruluğu şüphelidir. Onu az da olsa daha yakından tanımamızı mümkün kılan onun hakkında kayda girmiş iki tane mahkeme sicili vardır. Osman Efendi'nin vefatından sonra yazılan bu muhallefât kaydına göre onun ölümü 20 Nisan1806 (01.S.1221)'dır.

Osman Efendi'nin vefatında vâris olarak eşi Hatice Hanım ve baba tarafından bazı akrabalarının ismi geçmektedir. Gerek ilk eşi Emetullah Hanım (v.1770) binti Afif Efendi ve gerekse ikinci eşi Hatice Hanımdan çocuğu olmadığı veya kendisinden önce vefat ettikleri anlaş1lyyor. Osman Efendi'nin hat tarihlerine geçen hayat hikâyesi ise kısaca şöyledir:

"Dâmâd-1 Afif demekle ariftir. Dîvân-1 hümayûn hulefâsından Hoca-zâde Mustafa Efendi'den temeşşuk ve teallümle tarz-1 Şeyhâneye mâlik bir hattat olmuş. Müşârun ileyh kaviy-yi heykel ve dürüşt-endâm [bir kimse] olup zamanında o boy ve posta adam az imiş. Sultan Selim Han emriyle sancak-1 şerif için bir Mushaf-1 Şerif yazıp mükâfaat olarak bir kıt'a çelenge nâil olmuştur. Vefatı 1210 (1795/1796)'da Üsküdar'da [vâkı' olup] Şeyh Hamdullah merhum civarında medfundur..."1

\section{Osman Efendi’nin Mirasına İtiraz}

Afif damadı Osman Efendi'nin vefatını müteâkip meşru' vârisi durumunda olanlar arasında bir anlaşmazlık olmuştur. Bu itirazın en bariz sebebi ise Osman Efendi'nin çocuksuz vefatıdır. Böyle olunca da ona vâris olabilecek yakın akrabaları ister istemez devreye girip mahkemeden hak talebinde bulunmuşlardır. $\mathrm{Bu}$ itirazla ilgili olarak açılan davanın mahiyeti şöyledir:

"Medîne-i Üsküdar-1 meymenet âsârda Salacak İskelesi kurbünde Mirahur Mahallesi'nde sâkin iken bundan akdem vefat eden Hattat Afif Damadı Osman Efendi ibni el-Hac Osman'ın, zî-rahm cihetinden ber-vech-i âtî vârisi olduklarını iddia eden es-Seyyid Emrullah Efendi ve es-Seyyid Ali ibni Veliyyüddin'in meclis-i şer'-i şerîf-i enverde müteveffâ-yı mezbûrun zâhirde zevce-i menkûha-i metrûkesi Şerife Hatice Hatun ibnetü Süleyman'dan gayri vâris-i ma'rufu olmayıp terekesinin rub'u zevcesi mezbûreye mevrûs ve selâse irbâ'1 cânib-i bey-

1 Habib, Hat ve Hattâtan, Matbaa-i Ebüzziya, Kostantıniyye 1305, s. 162. 
tü'l-mâle ait olmak zu'muyle medîne-i mezbûrede bilâ vâris ma'rûf fevt olanların terekelerini kabza me'mur olmağla tereke-i müteveffâ-yı mezbûrun selâse irbâ'1na bi'l-emâne vaz'-1 yed ve ber-vech-i âtî husûmetten ve cevâba kıbel-i şer'den me'zûn olan hâlâ medîne-i mezbûre beytü'l-mal emîni Abdullah Ağa ibni Mehmed mahzarında üzerine da'vâ ve takrîr-i kelam edip müteveffâ-yı mezbûr Osman Efendi'nin babası mezbûr el-Hac Osman Efendi ile babamız mezbûr Veliyyüddin'in vâlidesi Aişe Hatun li-ebeveyn karındaşlar olup babaları ismi diğer Osman ve dedeleri ismi Abdullah ve vâlideleri ismi Fatma binti Abdullah ve maskat-1 re'sleri medine-i mezbûrede Bülbülderesi'nde Solaksinan mahallesi mezbûre müteveffâ-yı mezbûrun verâseti zevcesi mezbûre Şerife Hatice Hatun ile cihet-i mezkûreden bize ve li-ebeveyn karındaşımız olup gâib 'ani'l-meclis es-Seyyid Mustafa'ya münhasıra ve müteveffâ-yı mezbûre bizden gayri vâris ve terekesine müstahak âhır olmamağla müteveffâ-yı mezbûrun selâse irbâ' terekesinden hissemizi emîn-i mezbûrdan taleb ederiz. Sual olunsun dediklerinde gibbe's-suâl ve'l-istintâk emîn-i mezbûr cevabında tereke-i müteveffâ-yı mezbûrun selâse 'irbâ'1na bi'l-emâne vaz'-1 yedini ikrâr lakin müteveffâ-yı mezbûrânın ber-vech-i muharrer vâris müddeâ'larını külliyen ba'de'l-inkâr müddei'yân-1 mezbûrândan ber-vech-i muharrer müdde'âlarına beyine taleb olundukta udûl-i ahrâr-1 ricâl-i müslimînden Hâfız Molla Mehmed bin Hâfız Osman ve es-Seyyid Numan Ağa ibni el-Hac Abdülkaadir li-ecli'ş-şehâde meclis-i şer'a hâzırân olup eserü'l-işhâd filhakîka müteveffâ-yı mezbûr Osman Efendi'nin babası mezbûr el-Hac Osman Efendi ile müdde'iyân-1 mezbûrân es-Seyyid Emrullah efendi ve es-Seyyid Ali'nin babaları mezbûr Veliyyüddin'in validesi mezbûre Aişe Hatun li-ebeveyn karındaşlar olup babaları ismi mezbûr Osman ve dedeleri ismi Abdullah ve valideleri ismi Fatma binti Abdullah maskat-1 re'sleri mârru'z-zikr Bülbül Deresi'nde Solaksinan mahallesi olup müteveffâ-yı mezbûrun verâseti zevcesi mezbûre Şerîfe Hatice Hatun ile cihet-i mezkûrede işbu müdde'iyân-1 mezbûran es-Seyyid Emrullah Efendi ile es-Seyyid Ali ve karındaşları gâib 'ani'l-meclis es-Seyyid Mustafa'ya münhasıra [dır]. Müteveffâ-yı mezbûre mezbûrandan gayri vâris ve terekesine müstahak âhır olduğu malumumuz değildir. Biz bu hususa bu vech üzere şâhidleriz. Şehadet dahi ederiz deyu her biri edâ-i şehâdet-i şer'iyye ettikte ba'del-akd ve'd-tezkîr şehâdetleri makbûle olmağın mûcebince ba'de'l-hükm mâ vaka'a bi't-talep ketb olundu. 25 Ocak1806 (Fî 05.Za. 1220).

Şühûdü'l-hâl:

Es-Seyyid Ali Efendi

Molla Hasan

Muhzır Ali Ağa."’2

2 K1smet-i Askeriye $815 / 25$ b. 


\section{Afif Damadı Hattat Deli Osman'ın Muhallefâtı}

Afif Damadı Osman Efendi'nin vefatıyla Kısmet-i Askeriye mahkemesince yazılan muhallefâtında kayın pederinin aksine bir hilye dışında ne hat ve yazıya ne de kitaba dair pek bir şeyi yoktur. Sahip olduğu eşya da oldukça mütevâzı'dır. İşbu muhallefât şöyledir:

"Medîne-i Üsküdar-1 meymenet âsârda Salacak iskelesi kurbünde Mîrahur mahallesinde sâkin iken bundan akdem vefat eden Afif-zade dâmadı Hattat es-Seyyid Osman Efendi b. el-Hac Osman'nn verâseti zevce-i metrûkesi Şerife Hatice ibnetü Süleyman ile zî-rahm cihetinden müteveffâ-yı mezbûrun babası mezbûr Osman'ın li-ebeveyn kız karındaşı Âişe Hatun'un oğlu Veliyyüddin'in oğulları es-Seyyid Mustafa, es-Seyyid Emrullah es-Seyyid Ali'ye münhasıra olduğu şer'an zâhir ve ve mütehakkak olduktan sonra zevce-i mezbûre Şerife Hatice Hatun ve mezbûrûn ma'rifetleriyle tahrir ve bey' ve taksim olunan tereke-i müteveffâ-y1 mezbûrdur ki ber-vechi âtî zikr olunur. 20 Nisan 1806 (Fî gurre-i Safer sene 1221).

\begin{tabular}{|c|l|c|c|}
\hline & Eşyanın adı & Adedi & Fiyatı / Guruş \\
\hline 01 & Peştahta, pisştahta ve çalar saat & 01 & 0085.00 \\
\hline 02 & Mir’ât & 01 & 0010.00 para \\
\hline 03 & Levha 2, zamk taş1 & 01 & 0007.50 \\
\hline 04 & $\begin{array}{l}\text { Kitık memlû şayak yastık 9, minder 3, ma- } \\
\text { kat 2, pencere perdesi 3, hasır 1 }\end{array}$ & & 0053.00 \\
\hline 05 & Köhne çuka, seccade & 02 & 0003,04 para \\
\hline 06 & Kır at, çul 1, başl1k 1 & 00 & 0230.00 \\
\hline 07 & Şile kalbur & 01 & 0004.50 \\
\hline 08 & Hurdevât & 01 & 0001.00 \\
\hline 09 & Mâi çukalı eğer & 08 & 0012.00 \\
\hline 10 & Reşmiye ve yular & 02 & 0003.50 \\
\hline 11 & Kehrüba imameli dühan çubuk & 00 & 0028.00 \\
\hline 12 & Kanarya kafesi & 02 & 0001.04 para \\
\hline 13 & Külünk & 01 & 0003.01 para \\
\hline 14 & Taş imameli dühan çubuk & 00 & 0012.00 \\
\hline 15 & Çul belleme & 01 & 0009.00 \\
\hline 16 & $\begin{array}{l}\text { Köhne köşe minderi, kilim, çit parçası ve } \\
\text { hurdevat }\end{array}$ & 00 & 0008.50 \\
\hline 17 & Köhne çuka seccade & 01 & 0003.01 para \\
\hline
\end{tabular}




\begin{tabular}{|c|c|c|c|}
\hline 18 & Köhne yorgan & 04 & 0012.50 \\
\hline 19 & Çit yorgan & 02 & 0012.00 \\
\hline 20 & Köhne kutnu yorgan & 00 & 0003.02 para \\
\hline 21 & Beledi döşek & 01 & 0010.10 para \\
\hline 22 & Çit baş yastı̆̆ & 00 & 0004.02 \\
\hline 23 & Köhne sağîr minder & 01 & 0003.00 \\
\hline 24 & Kıbrıs-kârî yastık & 11 & 0040.00 \\
\hline 25 & Kıbrıs-kârî yastık 6, minder 3 & 00 & 0040.00 \\
\hline 26 & Fener taktuka 1,dühan tablası 2 & 00 & $0003.50 \mathrm{k} 10 \mathrm{p}$ \\
\hline 27 & Mangal & 01 & 0005.50 \\
\hline 28 & Çınar peştahta & 01 & 0007.00 \\
\hline 29 & Bir miktar kalem ve kâğıt & 00 & 0008.00 \\
\hline 30 & $\begin{array}{l}\text { Tencere } 4 \text {, abdest leğeni } 1 \text {, kahve ibriği } 1 \text {, } \\
\text { sahan } 9 \text {, kapak } 10 \text {, çorba kâsesi } 1 \text {, }\end{array}$ & 00 & 0050.00 \\
\hline 31 & Sözlü tâbe 1 , leğen 1 , şamdan tepsisi 1 , & 00 & 0003.00 \\
\hline 32 & Tas 1, enfiye kutusu ve mürekkep hokkas 1 & 00 & 0008.10 para \\
\hline 33 & Beyaz çarşeb & 01 & 0041.50 \\
\hline 34 & Sağîr şamdanlı gâş̧iye & 01 & 0025.00 \\
\hline 35 & Çuka şalvar & 01 & 0010.00 \\
\hline 36 & Çuka çakşır & 00 & 0020.00 \\
\hline 37 & Çuka kaplı kurt kürk & & 0040.00 \\
\hline 38 & Gezi kaplı nâfe cübbe kürk & 00 & 0028.50 \\
\hline 39 & Köhne (...) halâlî şal & 00 & 0020.00 \\
\hline 40 & Gezi kaplı cübbe, kakım kürk & 00 & 0031.50 \\
\hline 41 & Yeşil çuka biniş & 00 & 0025.50 \\
\hline 42 & Yeşil çuka cübbe & 01 & 0017.50 \\
\hline 43 & Sarı gez kaplı cübbe, sincap kürk & 00 & 0033.00 \\
\hline 44 & Eflatunî çuka biniş & 00 & 0047.50 \\
\hline 45 & Şâlî cübbe & 01 & 0012.00 \\
\hline 46 & Şâlî çakşır & 00 & 0013.00 \\
\hline 47 & Beyaz şâlî cübbe & 01 & 0007.50 \\
\hline 48 & Dülbent işleme entari & 00 & 0012.00 \\
\hline 49 & Çuka çakşır & 00 & 0025.00 \\
\hline 50 & Şâlî çakşır & 00 & 0007.00 \\
\hline
\end{tabular}




\begin{tabular}{|c|c|c|c|}
\hline 51 & Köhne entari & 01 & 0003.00 \\
\hline 52 & Beyaz çetârî entari & 00 & 0017.10 para \\
\hline 53 & Mâî şâlî biniş & 00 & 0012.10 para \\
\hline 54 & Köhne çuka gâşiye, terlik, sağîr kavuk & 00 & 0003.00 \\
\hline 55 & Hurdevât, örfiye / arakıye çift & 01 & 0003.00 \\
\hline 56 & Destar parçası & 02 & 007.50 \\
\hline 57 & Gömlek 2, don 2, uçkur 2 & 00 & 0013.50 \\
\hline 58 & Kebîr tahta sandık & 00 & 0007.50 \\
\hline 59 & Sağîr çalar saat & 01 & 0065.00 \\
\hline 60 & Sağîr piştov, çift 1 & 00 & 0023.00 \\
\hline 61 & Sandal parçası & 00 & 0002.50 \\
\hline 62 & Minder parças1 & 02 & 0007.00 \\
\hline 66 & Bir miktar yün & 00 & 0000.50 \\
\hline 67 & Çifte filinta & 01 & 0052.00 \\
\hline 68 & Def'a filinta & 01 & 0082.00 \\
\hline 69 & Bel tüfengi & 01 & 0060.00 \\
\hline & Yekûn & & $1550.50,13$ \\
\hline \multicolumn{3}{|c|}{$\begin{array}{l}\text { El-Hac Mehmed Ağa yedinde olup müteveffa-yı mezbûr zim- } \\
\text { metinde } 90 \text { guruş alacak mukabelesinde rehin olduğu ve meb- } \\
\text { lağ-1 merkûm müteveffâ-yı mezbûr Hattat Osman Efendi... } \\
\text { Zimmetinde alacak hakk1 olduğunu udûlden Mehmed b. Hü- } \\
\text { seyin ve Emrullah b. Hüseyin şehadetleriyle ber-nehc-i şer'î } \\
\text { ba'del-isbat (...) ahara bey' olunan bir helâlî saat ve } 7 \text { kalem- } \\
\text { tıraş ve bir sîm hokkalı kubur devât semeni }\end{array}$} & 0121.50 \\
\hline \multicolumn{4}{|c|}{ Ba'de'l-ihrâcât } \\
\hline \multicolumn{3}{|c|}{ Techîz ve tekfin } & 0050.00 \\
\hline \multicolumn{3}{|c|}{ Deyn-i müsbet el-Hac Mehmed (...) } & 0090.00 \\
\hline \multicolumn{3}{|c|}{ Delâliye-i eşyâ } & 0031.00 \\
\hline \multicolumn{3}{|c|}{ Harc-1 defter } & 0037.50 \\
\hline \multicolumn{3}{|c|}{ Sarrafiye } & 0002.50 \\
\hline \multicolumn{3}{|c|}{ Kaydiye-i defter } & 0002.00 \\
\hline \multicolumn{3}{|c|}{ Yekûn } & 0213.00 \\
\hline \multicolumn{3}{|c|}{ Son yekûn } & $1337,50,13$ \\
\hline
\end{tabular}


Müteveffâ-yı mezbûrun düyûn-i kesîresi olduğu ihbâr olunmağla [miras] taksimi düyûnun sübûtuna tevkîf olunup sahhu'l-bâki merkûm 1337,50 guruş 13 paranın 433,50 kuruş 13 parası 433,50 guruş 10 parası zevce-i mezbûre ile tarafindan vekîli Hâfız Abdurrahman Efendi zimmetlerinde ve 48 guruş 2 para tâbi-i merhûm Molla Mehmed zimmetinde ve 33 guruş 10 parası Hâfiz Çavuş Ağa zimmetinde ve 60 guruş tüfenk semeninden Genç Ali Ağa zimmetinde ve 76,5 guruş tabii muhzır Mustafa Ağa zimmetinde olup maadâ 687 guruş 11 para Bezzâzistan-1 Atîk ağasına vaz' olunduğu bu mahalle şerh olundu. Harrarahu'l-me'mur Dürrî-zade Seyyid Abdullah el-kaadı bi-asker-i Anadolu gufira lehüma."’3

Afif Damadı Hattat Deli Osman'ın arşiv kaynaklarında bir tek eseri görülebildi. O da 1807 tarihli Hâcegandan İbrahim Efendi'nin zeylinde yer alan Afif Damadı Osman Efendi hattı bir adet Mushaf-1 Şerif'tir. ${ }^{4}$

\section{Sonuç}

Sonuç olarak önce şunu net olarak belirtelim ki bizim sanat tarihimiz maalesef mechullerle doludur. Bu makaleye konu olan Hattat Osman Efendi de bunlardan birisidir. Burada verilen bilgilerle Hat ve Hattâtân'daki bilgiler kıyaslanınca gerçek ortaya çıkmaktadır. Bir sanatkâr için önde gelen özellik onun eserleridir. Ama bunun yanında onun özel hayatı da az çok bilinse fena mı olur? Bu makale Afif Damadı Osman Efendi'nin hiç olmazsa ölüm tarihini ortaya çıkardı. Damadı olarak hep adını zikrettiği Afif İbrahim Efendi ile arasındaki yakınlık daha da anlaşı1ır hâle geldi. Eşi Emetullah Hanım'ın adını ve kendisinden 37 sene önce vefat etmiş olduğu ortaya çıktı. Burada ortaya çıkan daha büyük bir gerçek ise Osman Efendi'nin son derece vefakâr bir insan olduğudur. Gerek kayınpederi ve gerekse hanımının onun üzerindeki tesirini bu kadar yıl yaşatmak her insanın yapacağı bir şey değildir. Bir de o günün sosyal hayatında geçerli olan ev hayatına ve ev eşyasına, yakın akrabalarına dair net ve kesin bilgilere ulaşıldı. 


\section{Kaynakça}

Kismet-i Askeriye 815 / 25 b.

K1smet-i Askeriye 812 / 46 b.

Kismet-i Askeriye 843 / 62.

Habib, Hat ve Hattâtân, Kostantıniyye, Matbaa-i Ebüzziya, 1305. 
Ek

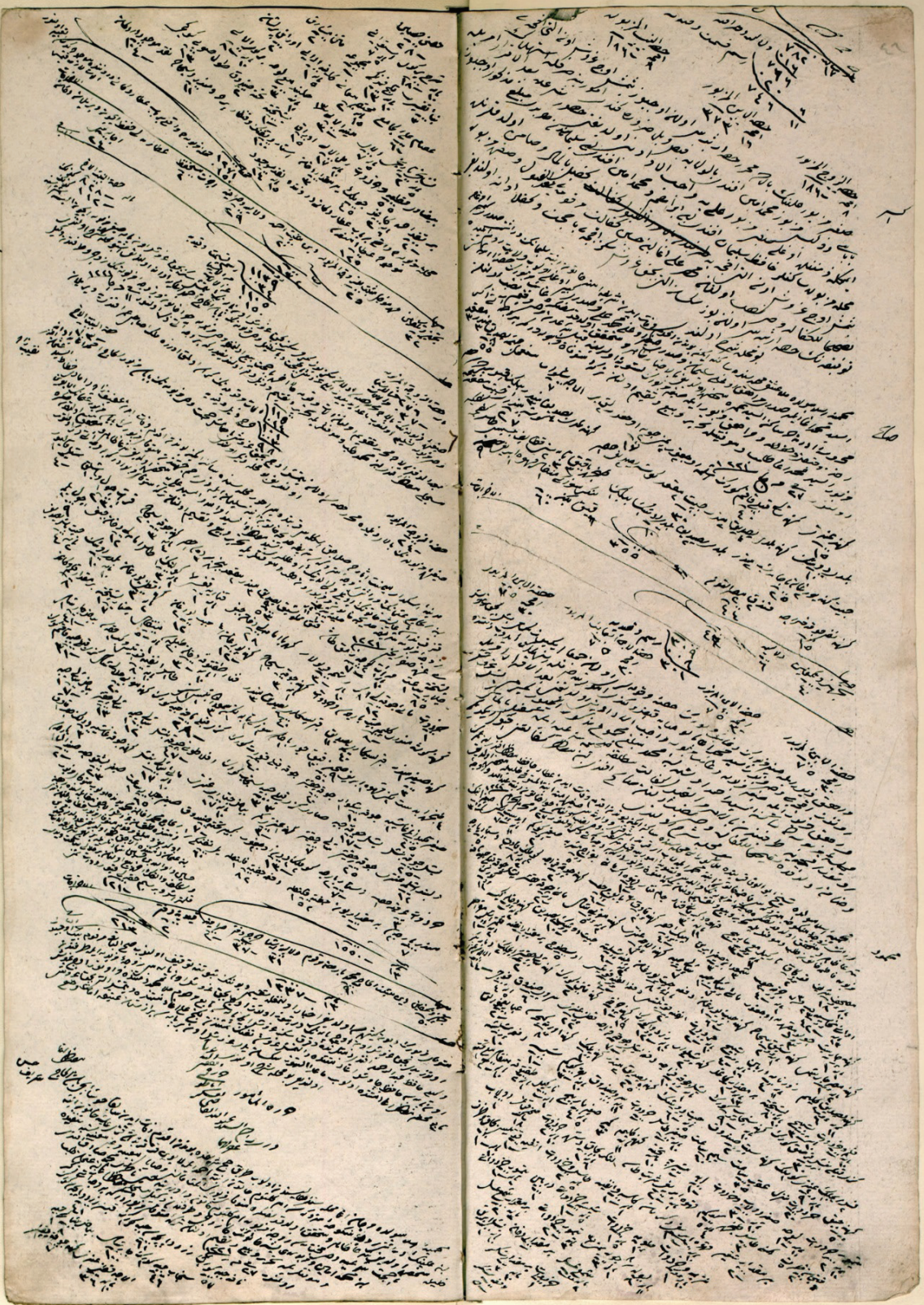




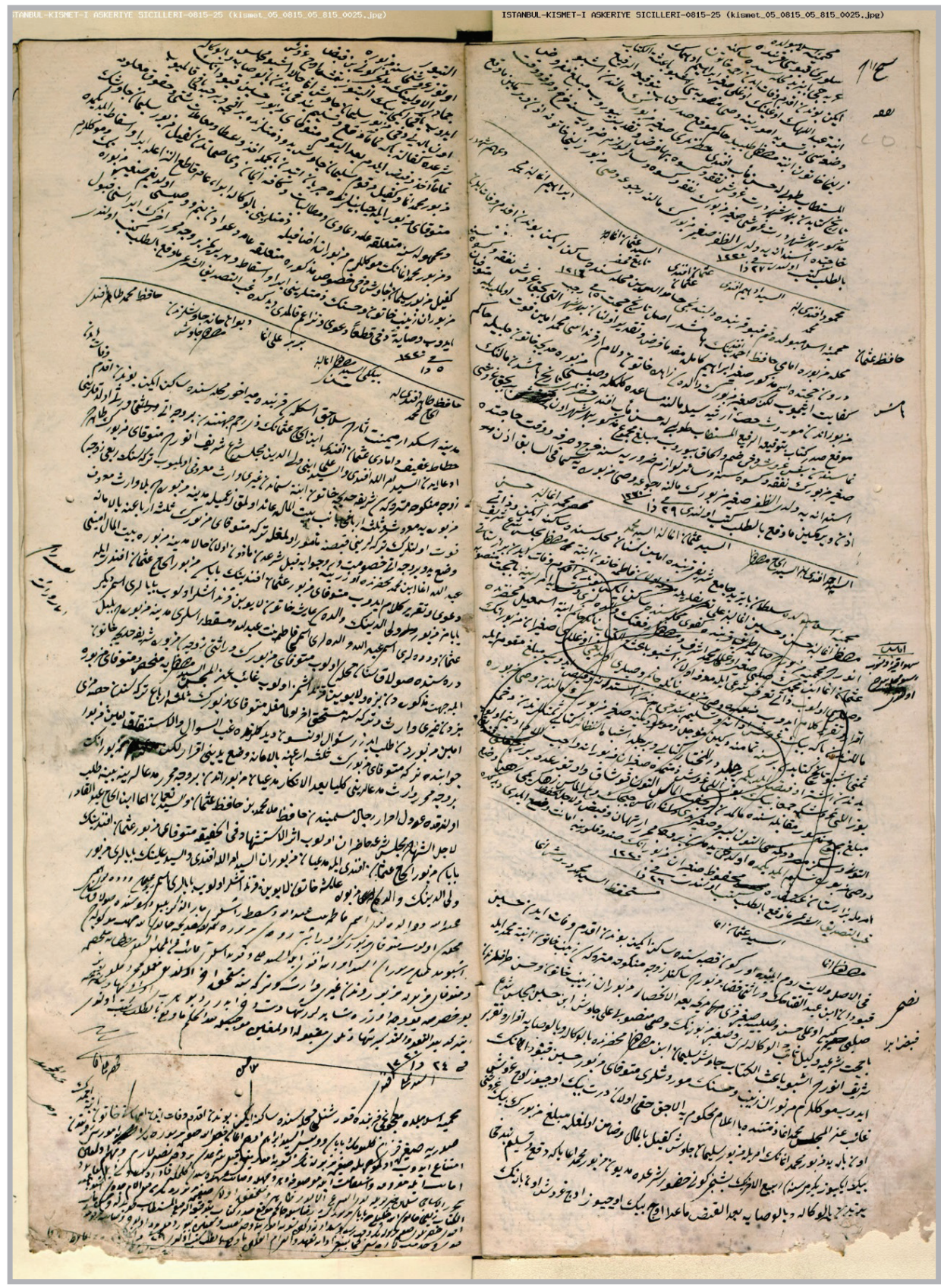

